\title{
NURSES' AWARENESS AND EXPERIENCES DURING THE COVID-19 PANDEMIC IN DUHOK CITY
}

\author{
Sara Jawad Kadhim ${ }^{1}$, Khalid Ibrahim Mohammed Saber ${ }^{2}$, Ronak Hassan Mohammed ${ }^{3 *}$ \\ 1. Department of clinical nursing, College of Nursing, University of Duhok, City of Duhok, Iraq. \\ 2. Department of clinical nursing, College of Nursing, University of Duhok, City of Duhok, Iraq. \\ 3. Department of clinical nursing, College of Nursing, University of Duhok, City of Duhok, Iraq.
}

\section{Corresponding author: Sara Jawad Kadhim}

Email: sara.kadhim@uod.ac

ORCID:

\section{ABSTRACT}

Background and aim: Nurses' awareness and experiences about covid-19 are essential aspects to facilitate their clinical practice, communicate and understand patients' needs. Awareness refers to the consciousness level of nurses that produces appropriate nursing implementation. Whilst experiences helps nurses adapt to work in a critical environment. The aim of the study was to assess nurses' awareness and experiences during the covid-19 pandemic.

Methods: It is a cross-sectional descriptive study design was conducted among nurses who are working at the teaching hospitals of Duhok city. The current study was carried out for four months, and the period of data collection lasted from 10th of June to 10th of October 2021. The data were taken from the participants by the direct interview method according to the questionnaire structured to the study.

Results: The finding refers that there was a significant correlation between the ages of participants with their awareness about covid-19. Also, Nurses' awareness was significantly affected by age and educational background. As for experience, no any noticeable effect and nurses stated that lack of staff and the provision of supplies during the covid-19 pandemic. .

Conclusion: Nurses' awareness and experience are essential at the time of managing covid-19 patients. They were having sufficient awareness level about the manner of infectious outbreak. Their demographic characteristics such as age and educational background also positively affected their awareness which made them devoted to providing nursing care in order to obtain a good recovery and control the pandemic.

Keywords: covid-19, pandemic, experiences, awareness

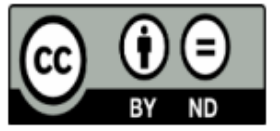

This work is licensed under a Creative Commons Attribution Non-Commercial 4.0 International License.

Received: 20 October 2021, Accepted: 11 December 2021, Available online: 20 January 2022 


\section{INTRODUCTION}

The covid-19 outbreak was reported in December 2019 in Wuhan, China Shu-Ching et al. (2020). It is infected most individuals around the countries, besides it is a globally challenging issues for health care systems Lord et al. (2021). Covid-19 virus is a communicable disease that causes illness and it is effortlessly transmitted by respiratory droplets at time of coughing, and sneezing (Balkhair, 2020). Nurses, who work during the pandemic in various departments, including medical, surgical, as well as critical units, are more vulnerable to infection, and there is a possibility of spreading the virus to their families, friends and relatives. Therefore, nurses must possess sufficient knowledge, awareness, experiences and preventive measure to control the spread of the virus Al-Dossary et al. (2020). Nurse's knowledge about covid-19 virus is essential for their safety, and increased their ability to give appropriate care for patients with confirmed infection Salman et al. (2020). The knowledge of nurses about coronavirus can be reflected significantly in their awareness and practices. Further, any misunderstanding regarding the awareness and practices increases the risk of infection transmission Zhang et al.(2020). The awareness and experience of nurses are essential aspects to facilitate their clinical practice, deliver an effective care to patients, as well as enable nurses to communicate and understand patients' needs. Hence, nurses' awareness refers to a degree of consciousness level that produces appropriate, and responsive nursing implementation that is considered empathic and patient centered. Whilst, nurses' experiences are a parameter that helps nurses adapt to work in a critical environment, especially they are working with confirmed cases of coronavirus patients that influence on their psychological, mental, social \& interpersonal relationships Ulrich et al. (2018). Healthcare providers are considered the most vulnerable to infection, exposure to many psychological stress, and physical problems as well as unexpected death, among them Bashir et al. (2020). In particular, nurses play a critical role in controlling covid-19 infection Mitchell et al. (2021). Nurses are one of the vital members of the health care system and they have direct contact with patients through providing nursing care, consultation, training, or education Buerhaus et al. (2020). Many factors facilitate the transmission of the infection among health care providers such as lack of awareness, insufficient personal protective barriers, overcrowded workplaces, absence of isolation rooms for providers, and environmental contamination Zhang et al. (2020). For that reason, the current study was conducted to assess nurses' awareness and their experiences during the covid-19 pandemic and prevent it spreads from patient to other or from patient to health care workers and even to their families.

\section{METHOD}

\section{-Design of the study:}

It is a cross-sectional study design was conducted to assess nurses' awareness, and their experiences about the covid-19 pandemic.

\section{-The setting and time of the study:}

This study was carried out among nurses who are working at teaching hospitals in Duhok City/ Kurdistan Region/ Iraq. The data collection was done for four months, lasted from 10th of June to 10th of October 2021.

\section{-Sample of the study}

A non-probability convenience sampling method of $(100)$ registered nurse where participated in the study from different level of education and work in a variety units of hospitals as medicalsurgical nurses, and critical care units.

\section{-Method of data collection}

The data were taken from the participants by the direct individualized interview method according to the questionnaire structured to the study. The survey was conducted in Kurdish and English languages; it took about 10 minutes to be completed. The questionnaire was composed of two parts:

The first part focuses on socio-demographic and clinical characteristics of nurses which were (Age, gender, level of education, marital status and area of work. As well as, experiences years of work as a nurse, working hours before and after covid19 pandemic. Whereas, the second part determine nurses level of awareness about covid19 in word of transmission mode of illness, causation, complication, and preventive measures, in which consist of (10 items), and nurses experiences after the covid-19 pandemic in terms of employment status, duties, and working hours, that consist of (8 items).The participants responded to the items of the questionnaire by "yes" and "no" approach, these items were designed according to prior published work. The modifications by researcher were applied to both items and scoring of questionnaire to facilitate assessment of participant awareness level and experiences after covid-19 crisis. 


\section{Statistical analysis}

The data were analyzed through the use of Statistical Package for Social Science (SPSS) software, version 24. Descriptive statistics were applied to summarize the demographic characteristics of the study sample involves the frequency, percentage, mean, and standard deviation. To determine the association between socio-demographic characteristics of nurses with their level of awareness and experiences, the coefficient correlation was conducted.

\section{Limitation of the study:}

There are some limitations which faced by the investigator during the period of study include firstly, most participants did not interest, and have no desire to participate in the current study. Also the shortage of staff, the lack of time for face to face interview with them, and workload in their departments which produce the effect on sample size in the current study. Second, possibility of inaccuracy in answer the items of questionnaire established by the researcher because the covid19 is still very recent and many nurses do not have enough experience towards it.

\section{RESULTS}

A hundred (100) nurses participated in the current study. The mean age of the nurses was 30 , and 6.7 of standard deviation. Regarding the gender of the study sample, most of them were male, which represented $(60 \%)$. Around $(45 \%)$ of participants have bachelor-degrees, whereas (42\%) of them graduation from nursing institute, and the remaining group composed of $(8 \%)$ and $(5 \%)$ of postgraduate and nursing school, respectively. The marital status distribution signified that (53\%) married nurses, while (46\%) among them were single. Concerning the working units of nurses, it was found that the majority of participants worked at critical units which existed $(42 \%)$, the number of nurses who work at medical units represented $(31 \%)$, and only $(9 \%)$ of the study sample worked in other hospital units. The mean score of nurses' year of experiences registered $(6.5 \%)$, with 5 of standard deviation. Again, the calculated mean of participants working hours per week before covid 19 was 36 , and it declined to 28 hours after covid19 pandemic, are shown in table (1).

Table two represents the correlation between socio-demographic characteristics of the study sample with their awareness and experience regarding covid-19 pandemic. The finding refers that there was a significant correlation between the ages of participants with their awareness about covid19. Also, level of awareness was significantly affected by nurses educational status with the ( $p$-value <0.05). Further, there was a non-significant correlation between working years of study sample with their awareness and experiences.

Table three revealed the nurses' experiences about the covid-19 pandemic, in which the highest percentage of nurses $(85 \%)$ responded by "yes" about their faced workload, understaffing as well as lack of resources during covid19 pandemics. Whereas, the lowest percentage of participants (52\%) answered by "yes" regarding to thought of leaving their job as a result of covid- 19 .

Table four shown the frequencies and percentages of the study samples responses according their awareness level about the covid-19 pandemic, most of nurses $(98 \%)$ had an excellent aware of that covid-19 is transmitted through the coughing way, following by two identical results which represented $(91 \%)$ of nurses responded by "yes" that virus is transmitted from a viral-infected person to a non-infected person, and by using an infected person tools. Whilst, the lowest percentage of nurses $(54 \%)$ had confidence that Duhok city could win the battle against the covid19 virus.

Table 1. Distributions the socio-demographic characteristic of the study sample

\begin{tabular}{|c|c|c|c|}
\hline \multicolumn{2}{|l|}{ Variables } & $\mathbf{F}$ & $\%$ \\
\hline \multicolumn{2}{|c|}{ Age (Mean 30, S. Deviation 6.7) } & 100 & 100 \\
\hline \multirow[t]{4}{*}{ Gender } & Male & 60 & 60 \\
\hline & Female & 40 & 40 \\
\hline & Total & 100 & 100 \\
\hline & Post- Graduate & 8 & 8 \\
\hline \multirow[t]{4}{*}{ Level of education } & Bachelor- Degree & 45 & 45 \\
\hline & Nursing Institute & 42 & 42 \\
\hline & School of Nursing & 5 & 5 \\
\hline & Total & 100 & 100 \\
\hline
\end{tabular}




\begin{tabular}{|c|c|c|c|}
\hline \multirow[t]{6}{*}{ Marital Status } & Married & 53 & 53 \\
\hline & Single & 46 & 46 \\
\hline & Divorced & 1 & 1 \\
\hline & Total & 100 & 100 \\
\hline & Critical care units ( ICU, CCU, HDU) & 42 & 42.0 \\
\hline & Surgical Units & 18 & 18.0 \\
\hline \multirow[t]{4}{*}{ Area of Work } & Medical Units & 31 & 31.0 \\
\hline & Maternal and Pediatric Units & 6 & 6.0 \\
\hline & Emergency Room & 3 & 3.0 \\
\hline & Total & 100 & 100 \\
\hline Years of Experience & \multicolumn{3}{|c|}{ (Mean 6.5, S. Deviation 5) } \\
\hline \multicolumn{3}{|c|}{ Weekly working hours before covid pandemic } & \\
\hline \multicolumn{2}{|c|}{ Weekly working hours during covid pandemic } & & \\
\hline
\end{tabular}

Table 2. Mean, Standard Deviation, and correlation between some demographics with nurses' Awareness and experience regarding Covid-

\begin{tabular}{|c|c|c|c|c|c|c|c|c|c|}
\hline Correlation & $M$ & $S D$ & Age & $M$ & $S D$ & $\begin{array}{l}\text { Nurses } \\
\text { Education }\end{array}$ & $M$ & $S D$ & $\begin{array}{l}\text { Years of } \\
\text { Experience }\end{array}$ \\
\hline Nurses' & 8 & 2 & $.246^{*}$ & 8 & 2 & $.224^{*}$ & 8 & 2 & .166 \\
\hline Awareness & & & .013 & & & .025 & & & .098 \\
\hline Nurses' & 5 & 1 & -.042 & 5 & 1 & -.016 & 5 & 1 & -.072 \\
\hline Experience & & & .679 & & & .878 & & & .479 \\
\hline
\end{tabular}

Table 3. Nurses' Experiences during Covid-19 pandemic Nurses' Experiences items

\begin{tabular}{llll}
\multicolumn{3}{c}{ Yes } & \multicolumn{3}{c}{ No } \\
\hline $\mathbf{F}$ & $\%$ & $\mathbf{F}$ & $\%$ \\
63 & 57.3 & 47 & 42.7
\end{tabular}

1. Have you previously had professional experience related to Chronic Inf $€ 63$ illness (e.g. Hepatitis virus, Human immunodeficiency virus (HIV)

\begin{tabular}{|c|c|c|c|c|c|}
\hline 2. & $\begin{array}{l}\text { Increased hours of employment per week as a result of the COVID - } 19 \\
\text { pandemics }\end{array}$ & 59 & 53.6 & 51 & 46.4 \\
\hline 3. & $\begin{array}{l}\text { Decreased hours of employment per week as a result of the COVID }-1 \text { ! } \\
\text { pandemics }\end{array}$ & 55 & 50 & 55 & 50 \\
\hline 4. & $\begin{array}{l}\text { Threatened termination of employment as a result of the COVID - } 19 \\
\text { pandemics }\end{array}$ & 65 & 59.1 & 45 & 40.9 \\
\hline 5. & Did you face workload, Understaffing and lack of resources & 85 & 77.3 & 25 & 22.7 \\
\hline 6. & Reductions in nursing role (fewer tasks to do) & 60 & 54.5 & 50 & 45.5 \\
\hline 7. & $\begin{array}{l}\text { Additional tasks within nursing role (more tasks to do)/or Having to do } \\
\text { non-nursing duties. }\end{array}$ & 78 & 70.9 & 32 & 29.1 \\
\hline 8. & Did you think about leaving your job as a result of COVID-19 & 52 & 47.3 & 58 & 52.7 \\
\hline
\end{tabular}


Table 4. Nurses' Awareness regarding Covid-19 pandemic

\begin{tabular}{|c|c|c|c|c|c|}
\hline & \multirow[t]{2}{*}{ Nurses' Awareness Items } & \multicolumn{2}{|c|}{ Yes } & \multicolumn{2}{|l|}{ No } \\
\hline & & $F$ & $\%$ & $F$ & $\%$ \\
\hline 1. & COVID-19 is transmitted because of immunodeficiency & 57 & 57 & 43 & 43 \\
\hline 2. & $\begin{array}{l}\text { COVID-19 is transmitted from a viral-infected person to a non-infected } \\
\text { another person }\end{array}$ & 91 & 91 & 9 & 9 \\
\hline 3. & COVID-19 is transmitted by coughing & 98 & 98 & 2 & 2 \\
\hline 4. & The disease is transmitted through touching and shaking Hands. & 85 & 85 & 15 & 15 \\
\hline 5. & The disease is transmitted by using an infected person tools & 91 & 91 & 9 & 9 \\
\hline 6. & $\begin{array}{l}\text { Elderlies and people with chronic diseases are more vulnerable to get the } \\
\text { COVID - } 19 \text { disease }\end{array}$ & 87 & 87 & 13 & 13 \\
\hline 7. & Do you think that COVID-19 will finally be successfully controlled? & 65 & 65 & 35 & 35 \\
\hline 8. & $\begin{array}{l}\text { Do you have confidence that Duhok city can win the battle against the } \\
\text { COVID-19 virus? }\end{array}$ & 54 & 54 & 46 & 46 \\
\hline 9. & Are you worried one of your family members may get an infection & 87 & 87 & 13 & 13 \\
\hline 10. & Do You think you will probably get the illness & 72 & 72 & 28 & 28 \\
\hline
\end{tabular}

\section{DISCUSSION}

The study examined nurses' awareness and experiences during the covid-19 pandemics in Duhok city. Some points were highlighted regarding the effect of the pandemic on nurses; it shows the socio-demographic characteristics of nurses, and their association with level of awareness and experience during crisis of covid19. Thus, the considerable findings of the current survey will be discussed and based on the similarities and differences with the evidence of available research also the perspective of other authors to support the findings of the current results.

During the period of the pandemic, the nurses faced many consequences, which greatly affected the working hours and quality of nursing care provided to covid-19 patients, and current results show that the presence of nurses in hospitals and their working hours were less during the period of the pandemic compared to the working hours before the misfortune of spreading the virus. This may be due to some reasons. Infection by the virus was ferocious and rapidly spreading; they did not have enough time to prepare and plan for it. Therefore, it is absolutely necessary to reduce working hours in order to protect workers in the health sector, particularly the nursing staff. Similarly, a study by (Thompson,2019), reported that the long working hours for nurses may produce psychological, physical, and mental stress; it may interfere with the quality of the nursing care provided. According to the review of Loibner et al.(2019) nurse's wearing personal protective equipment for long hours during their shift result in exhaustion, and it is resulted of nursing administration mistake. It is preferable to have a well-thought-out schedule and appropriate hours of work to avoid recurring pressures, and errors.

Regarding the findings of the current survey, there was no significant association between biographic data such as age, level of education, and years of experience with nurses' experience towards covid-19 patients. Whereas, some demographic characteristics were positively related to the awareness level of nurses, nurses age was significantly affected on their awareness level about covid-19.The possibilities of this finding may be participants were from young and middle age groups; those have more selfconfident, powerful and a positive approach to problem solving. Also, they took active roles to help, and support patients in critical situations like corona virus. Comparably, a study carried out by Dalky et al. (2021) showed agreement with the current finding; they observed that the mean age 31 of nurses was significantly associated with their level of awareness. They clarified in their findings; nurses were in a state of readiness, well prepared for covid-19, as well as their satisfaction with the quality of the full configuration within their health sector. In contrast, another study found that older nurses had higher rates of awareness Almutairi et al. (2015).

Consequently, there was a significant association between nurses with a bachelor's degree or more and their awareness regarding covid-19 outbreak. The degree of education played a big role in the perception of the nurses to the phenomenon of illness, and administration of care on a continuous basis, along with helped to know how to minimize the complications of virus and full recovery from it. The current result of the study was confirmed to the finding of Tripathi et al. (2020) revealed that the health care providers as nurses with higher educational level contributed to continuously raising awareness about corona virus, for instance they were have sufficient enough aware about symptoms, mood of infectious disease transmission and that infection is related to the respiratory system. Besides, they well- understand about the complication of disease that extends from difficulty of breathing to elevation of body temperature. Through nurses' education their awareness about the absence of the actual treatment or specific way to treat covid-19, they know that they can help through reducing the signs and symptoms of disease and that is by managing difficulties and strengthen patients' immunity against the virus. According to the current finding, nurses' awareness was not influenced by their years of 
experience. Conversely, a study by Al-Dossary et al. (2020) indicated that the working year of experience can shape nurses' awareness, and that it plays a significant role in enhancing the quality of care for critically ill patients.

Concerning to nurses experiences during the covid-19 pandemic, suggested that participants had somewhat of experience in managing infectious disease outbreaks. Current study showed that most nurses suffered from workload, understaffing and lack of resources. The possibilities cause is that frequent admission of patients and critical cases at that time, which led to an increase the responsibility on nurses, as well as longer working hours, a more stressful working environment, and inadequate medical materials that produce burden on them. Whereas, about half of the respondents thoughts about leaving their job as a result of covid-19. Despite the obstacles that the nurses face and the intense anxiety about the exacerbation of cases, they did not think to leave job or abandon their responsibilities and their humanitarian role toward the disease and helping patients.

In addition, nurses with a higher awareness were more willing to deal with covid-19 patients, contribution to the fastest recovery of patients and minimizing the exposure risk of the illness. In the current study, the majority of nurses were aware that covid-19 could be transmitted by coughing. But, few of them responded that they have confidence of Duhok city can win the battle against the covid-19 virus, and they have great hope for the control and recovery of the last patient. This finding was in agreement with a study done by Tripathi et al. (2020) stated that awareness level among their participants were an excellent, in which they aware that the most common way of virus transmission through human droplets as coughing \& contact with fecal or oral of infected person. They understood that direct communication with an infected patient was considered the main source to spreading of infection. Their hospital staff was sure of complete control of the pandemic and that is due to accuracy of nursing care with rapid response, and cooperation between health care providers.

\section{CONCLUSIONS}

To sum up, nurses play vital roles during covid-19 pandemic, despite the risk of being infected and transmission of illness to their families. Nurses persistence and humanity led them to never stop of provide nursing care in order to control cases and speed up the recovery of the covid patients. The participant's ages and educational background were associated with their awareness level regarding covid-19 pandemic. We suggested that awareness levels among nurses were good during pandemic, particularly the mood of virus transmission. Further, nurses showed fairly good experiences in caring for infectious disease outbreaks. In which, nurses suffer from workload, understaffing and lack of resources, also few of them thought to leave job, and neglect of their duties despite the seriousness of the epidemic and the rapid spread of covid-19 infection.

\section{ETHICAL CONSIDERATIONS COMPLIANCE WITH ETHICAL GUIDELINES}

The college approval letter was granted from the scientific committee at the University of Duhok/ College of nursing for the purpose of starting data collection, as well as verbal and signed consent were taken from each participant in the current study.

\section{FUNDING}

This research did not receive any grant from funding agencies in the public, commercial, or non-profit sectors.

\section{AUTHOR'S CONTRIBUTIONS}

Study concept; Writing the original draft;D ata collection; Data analysis and Reviewing the final edition by all authors.

DISCLOSURE STATEMENT: The authors report no conflict of interest.

\section{ACKNOWLEDGEMENTS}

We sincere appreciation and gratitude to all nurses who voluntarily participated in the research and those working in the various medical, surgical fields and critical care units for giving their time to answer the study questionnaire in an accurate and valuable manner. Also, their spirit of cooperation with us in order to help a researchers complete the study.

\section{REFERENCES}

Al-Dossary, R., Alamri, M., Albaqawi, H., Al Hosis, K., Aljeldah, M., Aljohan, M., ... Falatah, R. (2020). Awareness, Attitudes, Prevention, and Perceptions of COVID-19 Outbreak among Nurses in Saudi Arabia. International journal of environmental research and public health, 17(21), 8269. https://doi.org/10.3390/ijerph17218269

Almutairi, K.M., Al Helih, E.M., Moussa, M., Boshaiqah, A.E., Saleh Alajilan, A., Vinluan, J.M. and Almutairi, A., 2015. Awareness, attitudes, and practices related to coronavirus pandemic among public in Saudi Arabia. Family\&communityhealth, 38(4),pp.332-340.DOI: https:// doi. org/10.1097/FCH.000000000000008 2

Balkhair, A.A., 2020. COVID-19 pandemic: a new chapter in the history of infectious diseases. Oman medical journal, 35(2), p.e123. doi: 10.5001/omj.2020.41

Bashir, S., Alsultan, F., Iqbal, M., Alabdulkarim, N., Alammari, K., Almousa, A., Alsultan, A., Albaradie, R., Mir, A., Alregaiey, K. and Habib, S., 2020. 
Healthcare workers' knowledge and attitudes towards COVID-19 in Saudi Arabia. DOI: https://doi.org/10.21203/rs.3.rs-99869/v1

Buerhaus, P. I., Auerbach, D. I., \& Staiger, D. O. (2020). Older clinicians and the surge in novel coronavirus disease 2019 (COVID-19). Jama, 323(18), 1777-1778. doi:10.1001/jama.2020.4978 Dalky, H.F., Ghader, N., Al Kuwari, M., Alnajar, M., Ismaile, S., Almalik, M., Shudifat, R., Sanad, S., AlNsair, N. and Al Matrooshi, F., 2021. Assessment of the Awareness, Perception, Attitudes, and Preparedness of Health-care Professionals Potentially Exposed to COVID-19 in the United Arab Emirates. Journal of Multidisciplinary Healthcare, 14, p.91. doi: 10.2147/JMDH.S278479 Loibner, M., Hagauer, S., Schwantzer, G., Berghold, A. and Zatloukal, K., 2019. Limiting factors for wearing personal protective equipment (PPE) in a health care environment evaluated in a randomised study. PloS one, 14(1), p.e0210775. https://doi.org/10.1371/journal.pone.0210775 Lord, H., Loveday, C., Moxham, L., \& Fernandez, R. (2021). Effective communication is key to intensive care nurses' willingness to provide nursing care amidst the COVID-19 pandemic. Intensive and Critical Care Nursing, 62, 102946. https://doi.org/10.1016/j.iccn.2020.102946

Mitchell, B. G., Russo, P. L., Kiernan, M., \& Curryer, C. (2021). Nurses' and midwives' cleaning knowledge, attitudes and practices: An Australian study. Infection, disease \& health, 26(1), 55-62. https://doi.org/10.1016/j.idh.2020.09.002

Salman, M., Mustafa, Z., Asif, N., Zaidi, H.A., Shehzadi, N., Khan, T.M., Saleem, Z. and Hussain, K., 2020. Knowledge, attitude and preventive practices related to COVID-19 among health professionals of Punjab province of Pakistan. The Journal of Infection in Developing Countries, 14(07), pp.707-712. doi:10.3855/jidc.12878

Shu-Ching, C., Yeur-Hur, L., \& Shiow-Luan, T. (2020). Nursing perspectives on the impacts of COVID-19. Journal of Nursing Research, 28(3), e85. doi: 10.1097/jnr.0000000000000389

Thompson, B.J., 2019. Does work-induced fatigue accumulate across three compressed 12 hour shifts in hospital nurses and aides?. PLoS One, 14(2), p.e0211715. https://doi.org /10.1371/ journal . pone.0211715

Tripathi, R., Alqahtani, S.S., Albarraq, A.A., Meraya, A.M., Tripathi, P., Banji, D., Alshahrani, S., Ahsan, W. and Alnakhli, F.M., 2020. Awareness and preparedness of COVID-19 outbreak among healthcare workers and other residents of SouthWest Saudi Arabia: a cross-sectional survey. Frontiers in Public Health, 8, p.482. https://doi.org/10.3389/fpubh.2020.00482
Ulrich, B., Barden, C., Cassidy, L. and Varn-Davis, N., 2019. Critical care nurse work environments 2018: findings and implications. Critical Care Nurse, 39(2), pp.67-84.https: //doi.org /10.40 $37 /$ ccn2019605

Zhang, M., Zhou, M., Tang, F., Wang, Y., Nie, H., Zhang, L., \& You, G. (2020). Knowledge, attitude, and practice regarding COVID-19 among healthcare workers in Henan, China. Journal of Hospital Infection, 105(2), 183-187. https://doi.org/10.1016/j.jhin.2020.04.012 